\title{
Brook trout (Salvelinus fontinalis) response to wood removal from high-gradient streams of the Adirondack Mountains (N.Y., U.S.A.)
}

\author{
Dana R. Warren and Clifford E. Kraft
}

\begin{abstract}
A before-after, control-impact study was conducted to evaluate brook trout (Salvelinus fontinalis) response to the removal of debris dams and woody debris from an ice-storm-impacted stream system in the eastern Adirondack Mountains in New York State. A total of 10 reach pairs were established on two first-order streams, two second-order streams, and one third-order stream, all within the same watershed. Analyses, conducted separately for each stream order, used linear contrasts to compare differences in trout abundance between reference (upstream) and removal (downstream) reaches 1 month and 1 year after the manipulation. We expected trout abundance to decrease in removal reaches relative to reference reaches; however, responses varied temporally and with respect to stream order. Trout abundance had not changed significantly 1 month after removal. One year after removal, relative trout abundance had increased in the third-order stream, decreased in the second-order streams, and exhibited no significant change in the first-order streams. In areas with abundant boulders and preexisting habitat complexity, accumulated woody debris may have limited influence on trout abundance.
\end{abstract}

Résumé : Nous avons procédé à une étude de type BACI (avant-après, témoin-impact) pour évaluer la réaction de l'omble de fontaine (Salvelinus fontinalis) au retrait de barrages et de débris ligneux dans un système de cours d'eau affecté par une tempête de glace dans l'est des monts Adirondack. En tout, dix paires de sections ont été délimitées sur deux cours d'eau de premier ordre, deux de second ordre et un de troisième ordre, tous situés dans le même bassin hydrographique. Les analyses, menées séparément pour chaque ordre de cours d'eau, se basaient sur les contrastes linéaires pour établir les différences d'abondance des ombles entre les sections témoins (en amont) et les sections modifiées (en aval) 1 mois et 1 an après la manipulation. Nous avions prévu que l'abondance des ombles diminuerait dans les sections modifiées par comparaison aux sections témoins; cependant, les effets variaient dans le temps et en fonction de l'ordre du cours d'eau. L'abondance des ombles n'avait pas changé de façon significative 1 mois après la manipulation. Un an plus tard, l'abondance des ombles avait augmenté dans le cours d'eau de troisième ordre et décru dans les cours de second ordre, mais elle n'avait subi aucun changement significatif dans les cours d'eau de premier ordre. Dans les régions où il y a de nombreux blocs rocheux et où la complexité pré-existante est élevée,

l'accumulation de débris ligneux peut n'affecter que peu l'abondance des ombles.

[Traduit par la Rédaction]

\section{Introduction}

Woody debris influences both physical and biological features of forested stream ecosystems (Keller and Swanson 1979; Harmon et al. 1986; Wallace et al. 1995) and is generally recognized as a structural element that provides crucial habitat for stream salmonids (Bisson et al. 1987). To assess directly the influence of wood on salmonid populations in mid- to high-gradient (3-20\%) Adirondack streams in New York State, U.S.A., we evaluated changes in brook trout (Salvelinus fontinalis) abundance in response to the removal of naturally formed debris dams.

Large woody debris (LWD; wood $>10 \mathrm{~cm}$ in diameter and $1 \mathrm{~m}$ in length) and debris dams can increase stream-habitat complexity, influence pool formation, and retain both allochthonous and autochthonous material at the base of stream food webs (Bilby 1981; Montgomery et al. 1995; Sundbaum and Näslund 1998). During the 1980s, research in the Pacific Northwest and Alaska indicated that wood removal from streams decreased local salmonid populations (Dolloff 1986; Elliot 1986; Bisson et al. 1987). Subsequently, stream management in those regions moved away from wood removal and toward wood addition with only selective removal of logging slash (Maser and Sedell 1994; Ralph et al. 1994). Placing wood in streams has been used for a number of years as a management tool to increase habitat for salmonids (Hunt 1976; Burgess and Bider 1980; Riley and Fausch 1995), but the response to wood addition has varied with

Received 16 July 2002. Accepted 26 February 2003. Published on the NRC Research Press Web site at http://cjfas.nrc.ca on 29 May 2003.

J16992

D.R. Warren ${ }^{1}$ and C.E. Kraft. Department of Natural Resources, Cornell University, Ithaca, NY 14853-3001, U.S.A.

${ }^{1}$ Corresponding author (e-mail: drw23@cornell.edu). 
species, age, and size of fish and pre-addition stream conditions (Riley and Fausch 1995; Solazzi et al. 2000; Roni and Quinn 2001).

Few studies have evaluated the role of wood in creating fish habitat in northeastern North America (Nislow et al. 1999), and the relationship between wood and fish is not well established for the high-gradient streams typical of this region. In January 1998, an ice storm in northern New York State damaged forest canopies, resulting in an increased frequency of debris dams and LWD loading in streams (Kraft et al. 2002). While most wood-addition studies have evaluated the effects of wood placed and anchored in streams, the 1998 ice storm provided an opportunity to assess naturally deposited wood structures and determine their role in creating trout habitat in a boulder-dominated system.

In this study we removed wood from streams within the region where ice-storm damage occurred to determine the influence of naturally deposited woody debris and debris dams on trout abundance. Based on previous research examining both addition and removal of wood from streams, we developed two primary hypotheses: (1) LWD and debris dams create pools and (or) increase habitat complexity favorable for trout, and (2) removal of woody debris decreases trout abundance in treatment reaches relative to paired reference reaches.

\section{Methods}

\section{Study site}

The study was conducted in a high-gradient watershed (area $\approx 17 \mathrm{~km}^{2}$ ) in the High Peaks region of the eastern Adirondack Mountains. The mainstem stream is a third-order tributary of the East Branch of the Au Sable River, which drains into Lake Champlain. Data were collected from two first-order streams, two second-order streams, and the single third-order stream (Fig. 1). Historical land use within the watershed includes forestry and some farming. The studyarea forests are currently designated "wilderness" in the upper elevations of the watershed, and are managed with selective logging at lower elevations, where our work was conducted. Study reaches were bordered by unmanaged riparian buffers $5-20 \mathrm{~m}$ in width, dominated by second-growth hardwood-coniferous trees approximately $50-80$ years old. The four dominant riparian tree species in the study area were eastern hemlock (Tsuga canadensis), white pine (Pinus strobus), red maple (Acer rubrum), and white birch (Betula papyrifera). Bedrock geology in the region is dominated by metamorphic rock, and glacial till is abundant throughout the region. Study reaches have predominantly cobble-boulder substrate with a pool-cascade-dominated flow regime. Streams in this region are characterized by a peak flow following snowmelt in April or May. Base flow occurs in July and August with a slight recharge in the fall.

Fish diversity is low in study streams: brook trout and slimy sculpin (Cottus cognatus) were the only two fish species present. Brook trout were found in all stream reaches and ranged from 34 to $206 \mathrm{~mm}$ total length (TL). Since sculpins were not ubiquitous and capture probabilities were low and inconsistent, their response to wood removal was not evaluated.
Based a 1999 survey of watersheds in the region (Kraft et al. 2002), the study watershed incurred relatively intense icestorm damage and subsequent wood deposition in streams. We consider the study watershed to be geomorphically and ecologically representative of other high-gradient streams in the eastern Adirondack Mountains.

\section{Study design}

We used a before-after, control-impact (BACI) design to assess the response of trout abundance to debris-dam removal (Underwood 1994). Ten pairs of reaches were selected for this aspect of the study. Each pair contained a reference reach where wood remained for the duration of the study and a removal reach where wood was left in the stream during initial surveys, then removed after 2 months. A total of four reach pairs were established for both the first- and the second-order streams (two pairs in each stream, two streams per order; Fig. 1) and two pairs were established on the sole third-order stream (Fig. 1). All study reaches contained debris dams that were expected to influence stream flow, pool formation, and trout abundance. Because of the high frequency and smaller size of debris dams in first-order streams (Bilby and Likens 1980), specific debris dams did not dominate a particular first-order reach. Therefore, $30 \mathrm{~m}$ long reaches were randomly selected in each of the two firstorder streams. To minimize variation between reaches, adjacent sections were paired. Second- and third-order reaches were centered on specific large debris dams that clearly altered flow in some way and created at least some pooled water at high flows (when reconnaissance surveys were conducted). Reference and impacted reaches were selected and paired on the basis of proximity and similarity in debris-dam function. Reaches within each pair had equal numbers of pool-riffle sequences above and below the dams. The distance between reference and removal reaches varied with stream size and pairs. Pairs were $30 \mathrm{~m}$ apart in the first-order streams, varied from $20 \mathrm{~m}$ apart to $80 \mathrm{~m}$ or more in the second-order streams, and were $>100 \mathrm{~m}$ apart in the thirdorder streams.

The two subwatersheds containing the two second-order and two first-order streams evaluated in this study had similar amounts of ice-storm damage, as well as similar abiotic and biotic conditions. We made the assumption that streams of the same order were more similar to each other than were streams of other sizes, and that the variability of reach pairs far apart within a given stream would be similar to that of reach pairs within a given stream order. These assumptions were made during the study-design phase, owing to constraints on the number of available streams and potential wood-removal sites in the study watershed.

Trout abundance was estimated at all sites twice prior to wood removal and three times following wood removal (Fig. 2). Pre-removal data were collected in June 2000 (round 1) and July 2000 (round 2). In August 2000, debris dams and any additional woody debris less than $30 \mathrm{~cm}$ in diameter were removed from the downstream reach in each pair (hereinafter "removal reach"). Owing to logistical limitations, a few individual pieces of LWD greater than $30 \mathrm{~cm}$ in diameter were left suspended above the water within the bankfull channel following removal. We tested for impacts of wood removal 1 month and 12 months after the initial 
Fig. 1. Rocky Branch watershed in the eastern Adirondack Mountains ( $\left.44^{\circ} 21^{\prime} \mathrm{N}, 73^{\circ} 41^{\prime} \mathrm{W}\right)$. Thick solid lines across streams indicate locations of reference reaches; thick broken lines indicate wood-removal reaches. Stream order (1-3) and reach pair (A-D) within order are indicated. "No-wood" reach pairs are also shown in the second-order section of McNalley Brook (2NWa and $2 \mathrm{NWb})$. The inset map shows the study location in New York State, U.S.A.

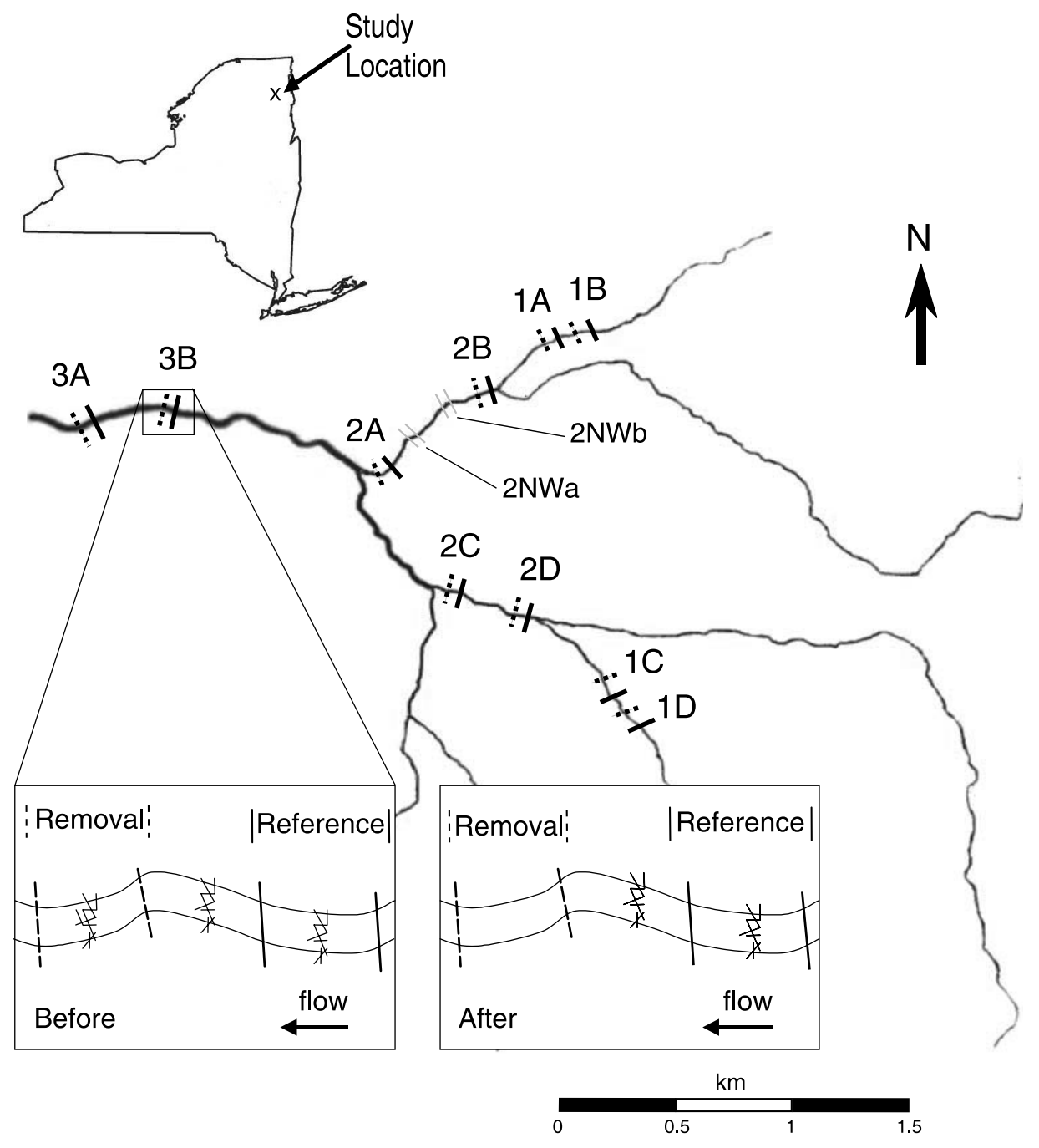

surveys by assessing changes in the difference in trout abundance between reference and removal reaches. Surveys in September 2000 (round 3) evaluated the 1-month impact (hereinafter "1-month response") (Fig. 2). Surveys in June 2001 (round 4) and July 2001 (round 5) assessed the impact of wood removal 1 year after the initial surveys (hereinafter "1-year response") (Fig. 2). Within each time period, we assessed responses separately for first-, second-, and thirdorder streams. Within each stream order, we assessed the response in terms of both total trout abundance and young-ofyear (YOY) trout abundance.

The upstream reach of each pair served as a reference to determine if changes in manipulated stream sections were a response to the "impact" or to factors unrelated to the removal of debris dams and woody debris (e.g., seasonal or yearly population fluctuations). Because of the potential downstream impact of sediment released following upstream dam removal, reference reaches were always located upstream of removal reaches. To ensure that responses in trout abundance were attributable to a lack of debris dams rather than to activities associated with wood removal, woody de- bris and debris dams were disturbed but not removed in the upstream reference reaches. A buffer section of stream with at least one channel-spanning debris dam separated all reach pairs. Within a pair, a debris dam occurred in all but one case between reference and removal reaches.

Four reaches (two pairs) $25 \mathrm{~m}$ in length were established in stream sections where woody debris was naturally absent (pairs $2 \mathrm{NWa}$ and $2 \mathrm{NWb}$ in Fig. 1). The "no-wood" reaches were intended to provide a comparison for expected trout abundance in wood-removal reaches. Reaches were similar in geomorphology to the reaches with wood and contained two full poolriffle sequences. Substrates were boulder-dominated, with pool-cascade/pool-riffle flow regimes. In no-wood reaches, fish were collected during rounds 1 (pair $2 \mathrm{NWb}$ only), 2 , and 3 of electrofishing. Fish abundance was compared between the two no-wood reaches and the nearest reach pair from the BACI study (Fig. 1).

\section{Data collection}

Brook trout abundance was estimated in all 24 reaches (20 BACI design, 4 no-wood reaches) by blocking the upstream 
Fig. 2. Timeline indicating pre- and post-removal activities associated with the before-after, control-impact (BACI) study. Wood was undisturbed in all reaches over two survey periods: June and July 2000. Wood removal occurred during August 2000. Post-removal assessments were conducted over three survey periods: September 2000, June 2001, and July 2001.

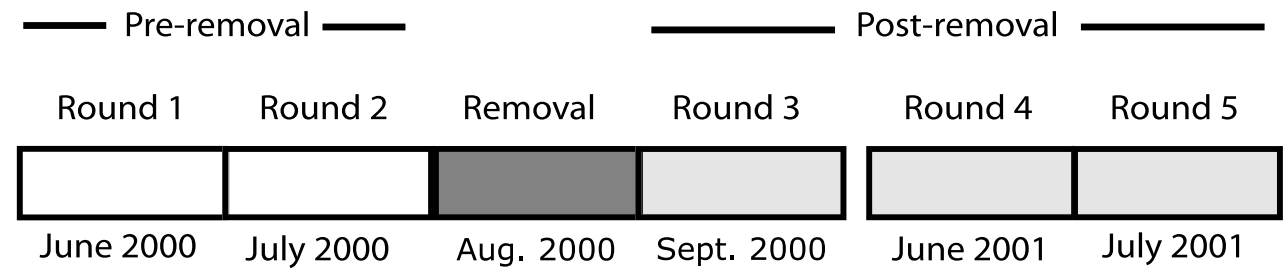

and downstream ends of the reach, then conducting threepass depletion fish population estimates with a backpack electroshocker. Overall trout abundance, YOY trout abundance, and the probability of capture were estimated with a derivation of the method of Carle and Strub (1978), using maximum weighted likelihood depletion estimates (Roni and Quinn 2001). Owing to the length of the stream sections in third-order reaches, abundance estimates were conducted separately above and below the central dam, and then summed. Fish were collected through the entire reach in both the firstorder and the second-order streams. Trout were anaesthetized and TL (mm) was recorded for every fish. YOY fish were distinguished from older fish by their conspicuously smaller size and distinct parr markings. During each round of electrofishing, all unmarked trout greater than $65 \mathrm{~mm}$ TL (age $1+$ or older) received a fin clip designating the tributary system of capture (three different clips). A total of 1583 brook trout $1+$ and older were clipped in the course of this study. For rounds $2-5$, the total number of clipped and unclipped fish was recorded for each reach.

In late August 2001, pool characteristics were evaluated along second- and third-order streams with survey reach lengths of 200 and $300 \mathrm{~m}$, respectively. Pools were defined during low-flow conditions as areas of low water velocity with a minimum depth of $20 \mathrm{~cm}$, based on habitat assumed to be capable of providing flow refuge for brook trout $>150 \mathrm{~mm}$ TL (Grant et al. 1990; Montgomery et al. 1995). For each pool we evaluated the following characteristics: pool location along the reach; whether the pool was formed predominantly by boulder, LWD, or a natural channel meander; approximate pool area; maximum pool depth; approximate maximum diameter $(\mathrm{m})$ of the largest and smallest pool-forming elements; and dominant substrate (boulder, $>40 \mathrm{~cm}$; large cobble, 20-40 cm; small cobble, 6-20 cm; pebble, 2-6 cm; gravel, $0.2-2 \mathrm{~cm}$; sand, $0.06-0.2 \mathrm{~cm}$; or silt and clay, $<0.06 \mathrm{~cm})$.

\section{Analyses}

Changes in the difference in trout abundance between reference and removal reaches were used to evaluate the impacts of wood removal. Although we hypothesized a decrease in overall brook trout abundance, we decided to use the more conservative two-tailed tests in our analyses. We expected that the role of wood and the response to wood removal would vary with stream size, so analyses were conducted separately for the first-, second-, and third-order streams.

One-month and 1-year responses were assessed using linear contrasts that compared the following for the first-, second-, and third-order streams: (1) the mean difference in estimated total brook trout abundance per reach between reference and removal sites before (June and July 2000) and after (September 2000, June and July 2001) the manipulation; and (2) the mean difference in the estimated number of YOY brook trout per reach between reference and removal sites before and after the manipulation. The unit of replication in this study was the reach pair. The values used in the BACI analyses were differences in trout abundance between reference and removal reaches (i.e., reference-reach abundance minus removal-reach abundance) rather than absolute population estimates.

The 1-month response was evaluated using the following linear contrast:

$$
\frac{\mu_{1 j}+\mu_{2 j}}{2}-\mu_{3 j}=0
$$

where $\mu$ equals the mean of the pairs' difference in estimated trout abundance between reference and removal reaches (four pairs in the first- and second-order streams; two pairs in the third-order stream). The subscripts 1, 2, and 3 refer to rounds 1,2 , and 3 of data collection corresponding to June 2000, July 2000, and September 2000, respectively, and the subscript $j$ refers to stream order (first, second, or third). This contrast tested the null hypothesis that the mean difference in trout abundance between reference and removal reaches had not changed 1 month after wood removal. The fixed effects in the analysis of variance (ANOVA) for this contrast were round, stream order, and the round $\times$ stream order interaction $(2,2$, and 4 degrees of freedom, respectively).

The analyses of the 1-year response were conducted using a similar linear contrast:

$$
\frac{\mu_{1 j}+\mu_{2 j}}{2}-\frac{\mu_{4 j}+\mu_{5 j}}{2}=0
$$

where $\mu$ equals the mean of the pairs' difference in estimated trout abundance between reference and removal reaches (four pairs in the first- and second-order streams; two pairs in the third-order stream). The subscripts $1,2,4$, and 5 refer to rounds $1,2,4$, and 5 of data collection, and the subscript $j$ refers to stream order (first, second, or third). This contrast tested the null hypothesis that the mean difference in trout abundance between reference and removal reaches had not changed 1 year after wood removal. Similar contrasts were also used to test for changes in the probability of capture in streams of each of the three sizes 1 month and 1 year after wood removal. As in the 1-month contrast, the ANOVA fixed effects for this contrast were round, stream order, and the round $\times$ stream order interaction $(3,2$, and 6 degrees of 
freedom, respectively). All analyses were conducted using SAS (version 8.2; SAS Institute Inc. 1999-2001).

Small sample sizes often preclude testing assumptions of a linear contrast, therefore statistical significance for linear contrasts was assessed using a randomization test when linear contrast $p$ values were $<0.2$ or $>0.01$ (Manly 1997). The $t$ value from the initial linear contrast was compared with $t$ values from 1000 other linear contrasts, each corresponding to a different random association of the difference values within sites. The $p$ value from the randomization was determined according to the percentage of the randomly generated $t$ values that were greater than the $t$ value from the contrast using the observed data. A power analysis was not calculated because post-hoc tests for power have been strongly discouraged in recent literature (Gerard et al. 1998; Anderson et al. 2001).

All trout and YOY abundance analyses were conducted using the point estimate from three-pass depletion estimates of population. The $95 \%$ confidence intervals were not symmetrical because the lower end of the interval was truncated by the total number of individuals captured. Error bars are included in all figures to indicate the variability associated with point estimates of total trout population. Using the $95 \%$ confidence intervals from three-pass depletion estimates, comparisons of trout abundance were made between the nowood reaches and the BACI study reaches within the same second-order tributary. If the $95 \%$ confidence intervals overlapped, the differences between values were considered nonsignificant. If the confidence intervals did not overlap, the differences were considered significant.

Trout movement and the relative amount of immigration or emigration (or death) of age $1+$ trout were evaluated by comparing new and recaptured fish between reference and removal reaches. Since the number of individuals captured in a given reach can be affected by the probability of capture, numbers of clipped ("recaptured") and unclipped ("new") fish greater than $65 \mathrm{~mm}$ TL were weighted by the probability of capture for each reach during each time period, derived from the total population estimate in each reach for each time period. Using weighted values, ANOVA was then used to compare the numbers of new fish in removal and reference reaches for a given round and stream order.

The influences of different pool-forming elements on maximum pool depth and pool area were compared using ANOVA. The relationships between the size of pool-forming elements and maximum pool depth and pool area were analyzed using linear regression with aggregated data from all three reaches.

\section{Results}

One month after wood removal, brook trout abundance had not changed significantly between reference and removal reaches for any of the three stream orders $(p=0.20,0.11$, and 0.58 for first-, second-, and third-order streams, respectively). Although the overall 1-month response to wood removal was not statistically significant, trout abundance in three of the four first-order paired removal reaches increased relative to their reference reaches (Fig. 3; Table 1). In the second-order streams, one pair of reaches exhibited a dramatic decrease in trout abundance 1 month after wood re- moval, but the other three pairs showed less pronounced differences (Fig. 4; Table 1). The estimated overall 1-month response for first- and second-order streams was an increase of 7.0 (standard error $(\mathrm{SE})=5.2$ ) individuals per removal reach in the first-order streams and a decrease of 8.8 individuals ( $\mathrm{SE}=5.2$ individuals) per removal reach in the secondorder streams. One-month responses in third-order streams were inconsistent and nonsignificant (a decrease of 4.3 individuals ( $\mathrm{SE}=7.4$ individuals); Fig. 5). Similarly, no significant 1-month responses were found for YOY trout in streams of any of the three sizes $(p=0.23$. 0.36 , and 0.20 for first-, second-, and third-order pairs, respectively; Table 1).

One year after the initial surveys, the response in trout abundance varied between the first-, second-, and third-order streams (Figs. 3-5). In the first-order streams, overall trout abundance was not significantly different between reference and removal sites $(p=0.52$, estimated change in removal reaches $=+3.3$ individuals, $\mathrm{SE}=5.0$ individuals) (Fig. 3). Differences in YOY brook trout abundance between reference and removal reaches in the first-order streams also remained similar to those in the same time period 1 year earlier ( $p=0.68$, estimated change in removal reaches $=-1.3$ individuals, $\mathrm{SE}=3.3$ individuals; Table 1).

Trout abundance in the second-order reaches decreased significantly by an estimated 11.8 fish per reach in removal sites relative to reference sites 1 year after wood removal ( $\mathrm{SE}=5.0, p=0.03$; Fig. 4). About half of the total decrease in population was attributable to fewer YOY fish in removal reaches (an estimated decrease of 6.1 individuals per removal reach; $\mathrm{SE}=3.3$ individuals, $p=0.07$; Table 1).

The 1-year response to wood removal differed between the two third-order pairs (Fig. 5; Table 1). In the upstream pair, brook trout abundance increased dramatically following dam removal, but the downstream pair showed little response (Fig. 5). Total estimated trout abundance increased by approximately 20.8 fish in removal reaches relative to reference reaches 1 year after wood removal $(p=0.008, \mathrm{SE}=7.1$ fish), though this was largely due to differences in the upstream pair. The overall estimated number of YOY trout also showed a positive response to wood removal, primarily because of differences in the upstream reach $(\mathrm{SE}=4.7$ fish, $p=0.05$; Table 1). As in the second-order streams, YOY contributed to about half of the total change in brook trout abundance.

The probability of capture for trout did not change significantly between reference and removal reaches 1 month after wood removal for any of the three stream orders $(p>0.2)$. One year after wood removal, an approximately $15 \%$ difference in probability of capture was found between reference and removal reaches in the first-order and second-order streams, with a greater probability of capture in the woodremoval sites $(p<0.06)$. The probability of capture at the third-order sites remained approximately the same in both treatments (difference $=-0.03, \mathrm{SE}=0.11, p>0.5$ ).

Comparisons between the no-wood reaches and the reaches from the wood-removal manipulation indicated that both before and after wood removal, trout abundance in reaches naturally devoid of wood was similar to that in reaches with wood (Fig. 6). For this comparison the probability of capture was not significantly different between the reaches with and 
Fig. 3. Estimated brook trout (Salvelinus fontinalis) abundance (number per reach) in reference and removal reaches in first-order streams for each sampling period. Solid lines with solid squares represent reference reaches; broken lines with open squares represent removal reaches. The vertical dotted line indicates the time of wood removal. Error bars indicate 95\% confidence intervals. (a) Stream pair 1A. (b) Stream pair 1B. (c) Stream pair 1C. (d) Stream pair 1D.

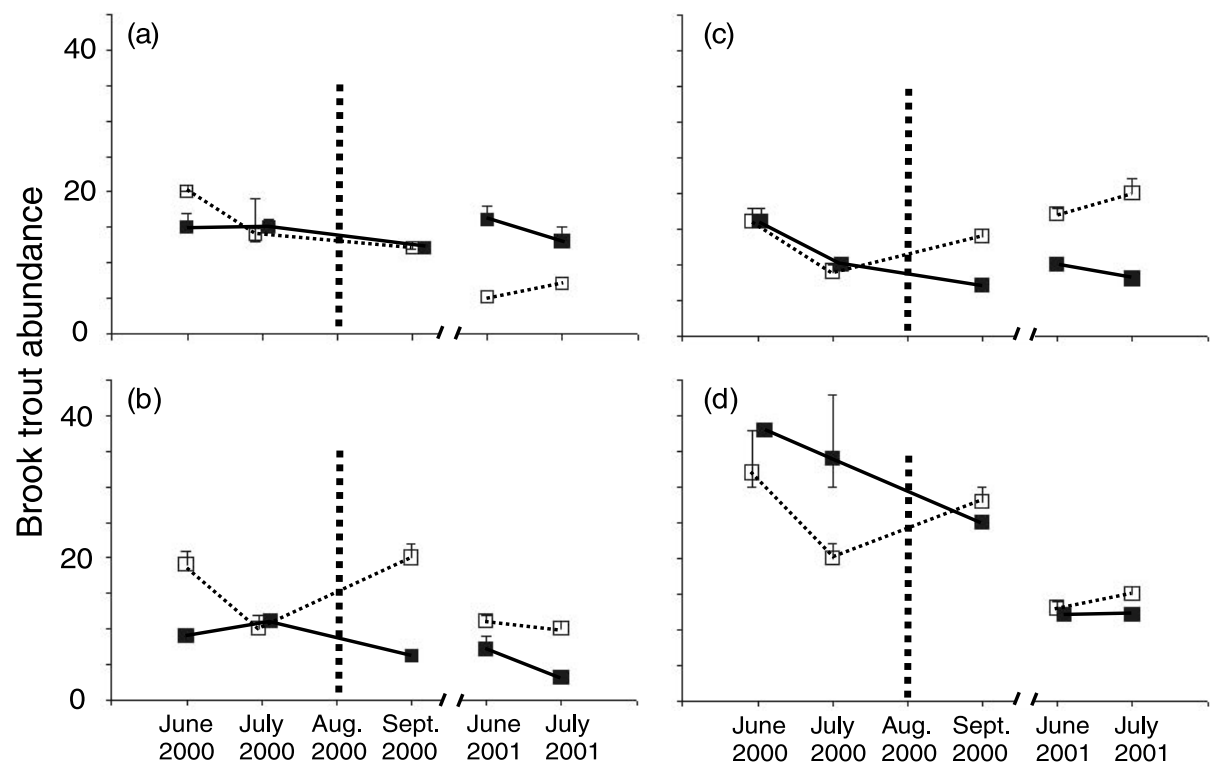

Table 1. Magnitude of the response to wood removal (difference in estimated fish abundance between reference and removal reaches before and after removal) in first-, second-, and third-order streams 1 month and 1 year after removal for the overall population, including young-of-year (YOY) and 1+ trout (difference in number of fish per reach), and the YOY trout alone (difference in number of YOY per reach).

\begin{tabular}{|c|c|c|c|c|c|}
\hline \multirow[b]{2}{*}{ Site } & \multirow[b]{2}{*}{$\begin{array}{l}\text { Mean reach length } \\
\text { of pair }(m)\end{array}$} & \multicolumn{2}{|c|}{ Overall population response } & \multicolumn{2}{|c|}{ YOY response } \\
\hline & & One month & One year & One month & One year \\
\hline $1 \mathrm{~A}$ & 31 & -2.0 & -10.5 & -2.5 & -8.5 \\
\hline $1 \mathrm{~B}$ & 30 & 9.5 & 1.0 & 0.0 & 0.5 \\
\hline $1 \mathrm{C}$ & 30 & 7.5 & 10.5 & 4.5 & 7.0 \\
\hline $1 \mathrm{D}$ & 31 & 13.0 & 12.0 & 6.0 & -4.5 \\
\hline $2 \mathrm{~A}$ & 34 & -4.0 & 4.5 & 1.5 & 2.0 \\
\hline $2 \mathrm{~B}$ & 39 & -32.0 & -19.5 & -5.5 & -10.0 \\
\hline $2 \mathrm{C}$ & 30 & -7.5 & -15.0 & -2.0 & 0.0 \\
\hline $2 \mathrm{D}$ & 24 & 8.0 & -17.0 & 0.0 & -16.5 \\
\hline $3 \mathrm{~A}$ & 71 & -10.0 & 2.0 & -1.5 & 2.5 \\
\hline $3 \mathrm{~B}$ & 82 & 1.5 & 40.0 & -4.5 & 22.0 \\
\hline $2 \mathrm{NWa}$ & 25 & -5.0 & & 1.0 & \\
\hline $2 \mathrm{NWb}$ & 25 & 3.0 & & 1.5 & \\
\hline
\end{tabular}

Note: Negative responses indicate that fish abundance decreased following wood removal. The mean reach length for each pair is provided for comparison.

without wood in any of the three rounds during which abundance was estimated $(p=0.34,0.58$, and 0.54 for rounds 1 , 2 , and 3 , respectively, $n=8$ ).

Previously unmarked age 1+ trout were captured at almost every site during all surveys. The weighted number of both new (unmarked) and recaptured trout did not differ significantly between reference and removal reaches during any collection period or for any stream size ( $p>0.1$ for all comparisons).

Boulders were the dominant pool-forming elements in this watershed (Table 2). Of 204 pools surveyed, 171 were formed by boulders alone, 27 were formed by the combination of boulders and LWD, 5 were caused by boulders and some other formation or process (e.g., channel meander), and only 1 pool was attributed to LWD alone. Loose large cobble (20-40 cm in diameter) was the dominant substrate in studyarea pools, regardless of the pool-forming element (Table 3). Pools formed by a combination of both boulders and LWD were not significantly different in maximum depth or in area from pools formed by boulders alone $(N=198, p=0.24$ and $p=0.85$, respectively). Additionally, maximum pool depth and pool area were not significantly different between the three stream sections surveyed $(N=204, p=0.21$ and $p=$ 0.49 , respectively) (Table 2 ). Pools were most often created 
Fig. 4. Estimated brook trout abundance (number per reach) in reference and removal reaches in second-order streams for each sampling period. Solid lines with solid squares represent reference reaches; broken lines with open squares represent removal reaches. The vertical dotted line indicates the time of wood removal. Error bars indicate 95\% confidence intervals. (a) Stream pair 1A. (b) Stream pair 1B. (c) Stream pair 1C. (d) Stream pair 1D.

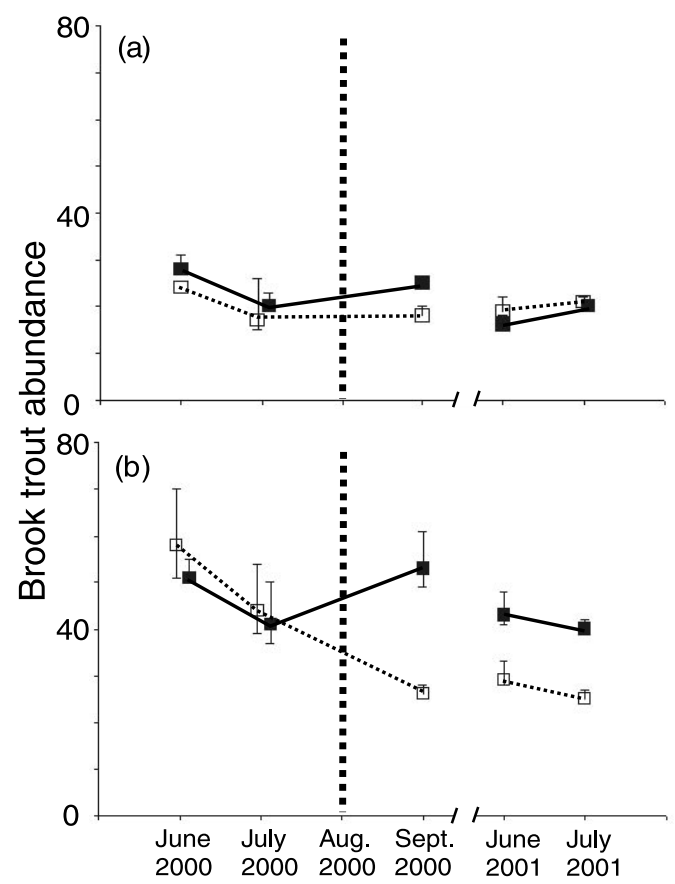

Fig. 5. Estimated brook trout abundance (number per reach) in reference and removal reaches in third-order streams for each sampling period. Solid lines with solid squares represent reference reaches; broken lines with open squares represent removal reaches. The vertical dotted line indicates the time of wood removal. Error bars indicate $95 \%$ confidence intervals. (a) Stream pair 1A.

(b) Stream pair 1B.

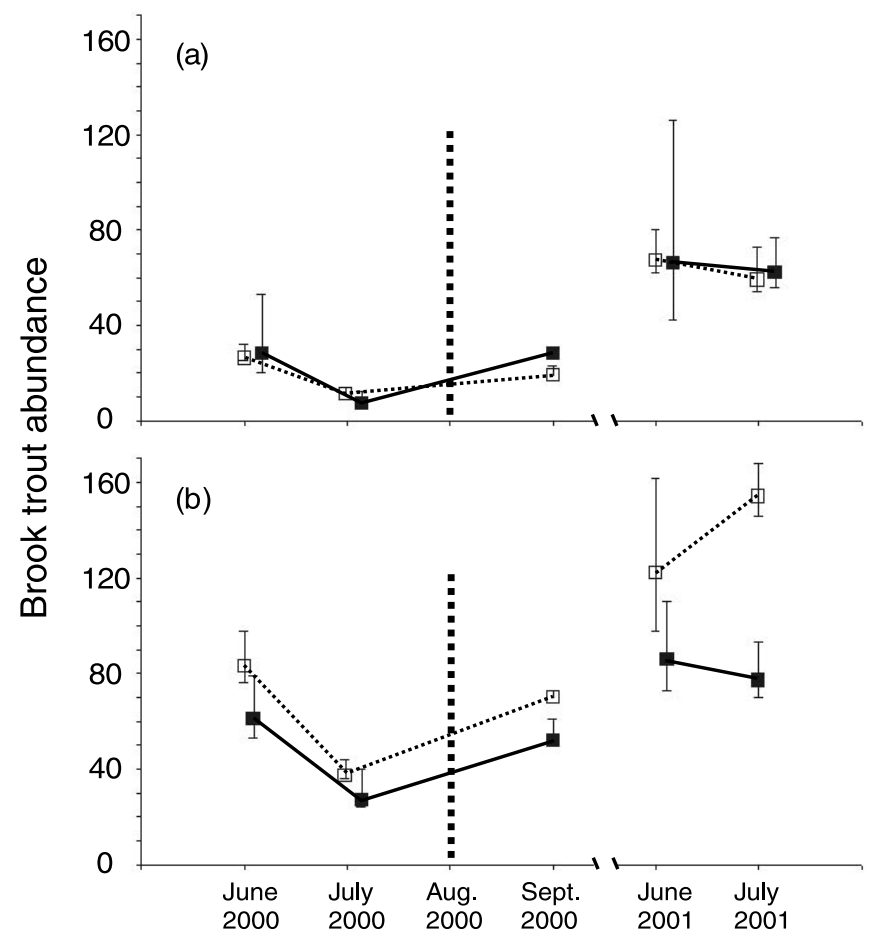

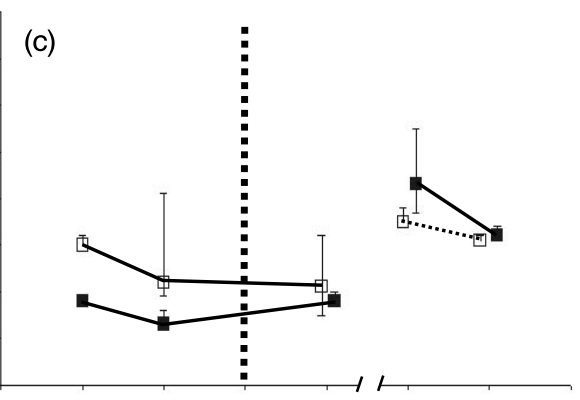

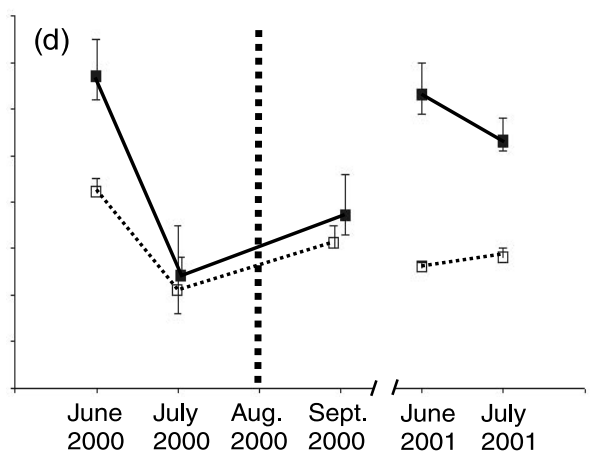

Fig. 6. Estimated brook trout abundances (number per linear metre of stream) in McNalley Brook reaches with and without wood. Squares represent the BACI reaches and triangles represent the nowood reaches. Open symbols indicate removal reaches in the BACI pairs and the downstream reach in the no-wood pairs. The vertical dotted line indicates the approximate date of wood removal. Error bars indicate $95 \%$ confidence intervals.

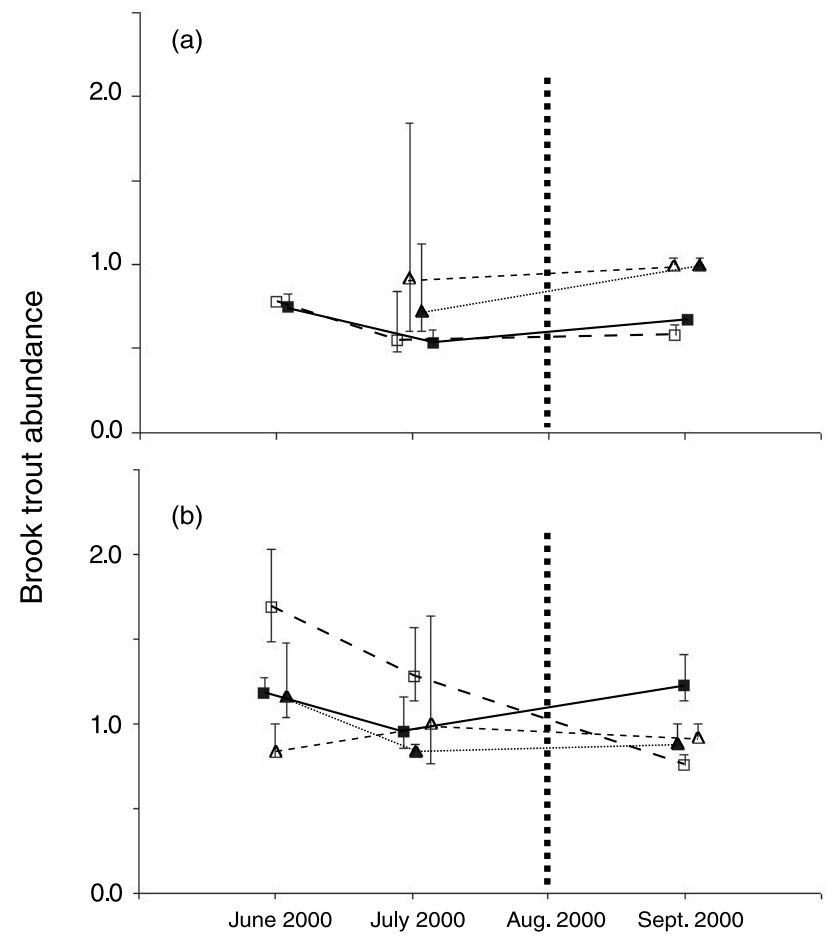


Table 2. Pool attributes from three streams in the Rocky Branch watershed (Adirondack Mountains, New York State).

\begin{tabular}{|c|c|c|c|c|c|c|c|c|}
\hline Stream & Order & $\begin{array}{l}\text { No. of } \\
\text { pools } / 100 \mathrm{~m}\end{array}$ & $\begin{array}{l}\text { Pool area } \\
\left(\mathrm{m}^{2}\right)^{a}\end{array}$ & $\begin{array}{l}\text { Max. pool } \\
\text { depth }(\mathrm{m})^{a}\end{array}$ & $\begin{array}{l}\text { Max. boulder } \\
\text { size }(\mathrm{m})^{a}\end{array}$ & $\begin{array}{l}\text { Pools from } \\
\text { boulders alone } \\
(\%)\end{array}$ & $\begin{array}{l}\text { Pools from } \\
\text { boulders } \\
\text { and wood } \\
(\%)\end{array}$ & $\begin{array}{l}\text { Bankfull } \\
\text { width }(\mathrm{m})^{a}\end{array}$ \\
\hline Rocky Branch & Third & 22.3 & $2.7 \pm 0.4$ & $0.34 \pm 0.01$ & $1.5 \pm 0.2$ & 82 & 10 & $11.3 \pm 1.1$ \\
\hline Rocky Branch & Second & 39 & $2.2 \pm 0.4$ & $0.31 \pm 0.01$ & $1.7 \pm 0.1$ & 86 & 14 & $8.0 \pm 0.5$ \\
\hline McNalley Brook & Second & 29.5 & $2.1 \pm 0.4$ & $0.32 \pm 0.02$ & $1.3 \pm 0.1$ & 85 & 12 & $6.1 \pm 0.7$ \\
\hline
\end{tabular}

Note: Survey reaches in second- and third-order streams were 200 and $300 \mathrm{~m}$ long, respectively. Max., maximum.

${ }^{a}$ Values are given as the mean $\pm 1 \mathrm{SE}$.

Table 3. Substrate composition of pools formed by the two primary pool-forming elements: boulders alone and boulders with woody debris.

\begin{tabular}{|c|c|c|c|c|c|c|c|}
\hline Pool-forming element(s) & Boulder & $\begin{array}{l}\text { Large } \\
\text { cobble }\end{array}$ & $\begin{array}{l}\text { Small } \\
\text { cobble }\end{array}$ & Pebble & Gravel & Sand & $\begin{array}{l}\text { Silt and } \\
\text { clay }\end{array}$ \\
\hline Boulders alone & $5(3)$ & 79 (46) & $53(31)$ & $9(5)$ & $5(3)$ & $15(9)$ & $5(3)$ \\
\hline Boulders with woody debris & $0(0)$ & $13(48)$ & $5(18)$ & $1(4)$ & $1(4)$ & $3(11)$ & $4(15)$ \\
\hline
\end{tabular}

Note: Total numbers of pools with a given dominant substrate are reported, with the percentage of the total in parentheses. Poolsubstrate data are aggregated from surveys of two second-order streams and one third-order stream in the Rocky Branch watershed (Adirondack Mountains, New York).

by two or more elements. Although the size of the largest pool-forming element was significantly related to pool area and maximum pool depth $(N=204, p<0.001$ for both $)$, the correlation was weak ( $r^{2}=0.07$ and $r^{2}=0.13$, respectively).

\section{Discussion}

Based on previous studies we expected to see reductions in brook trout abundance both 1 month and 1 year after wood removal (Elliot 1986; Bisson et al. 1987; Gowan and Fausch 1996). Instead, we found that the response of brook trout to the manipulation was complex and variable, with little consistent support for our hypotheses. Several debris dams in our study clearly impacted local trout abundance, though others appeared to have little influence. Whereas some of the dams formed in association with LWD that could be removed or cleared away, others formed against large boulders that retained pool-forming characteristics even after wood removal. Consequently, the role of boulders in pool formation likely contributed to the variable overall response seen in this study. The importance of boulders in creating habitat for trout has recently been noted in several observational studies that also initially focused on the role of LWD in streams (Berg et al. 1998; Inoue and Nakano 1998; Flebbe 1999).

Our pool-survey results support the contention that underlying geology is of primary importance in determining poolforming elements and the role of LWD, especially in mid- to high-gradient streams within young riparian forests (Grant et al. 1990; Flebbe and Dolloff 1995; Richmond and Fausch 1995). Most pools surveyed were formed by boulders or by both boulders and LWD. Study-area forests are relatively young, therefore most LWD, including wood deposited from the 1998 ice storm, was less than $30 \mathrm{~cm}$ in diameter. By contrast, boulders in this system regularly exceeded $70 \mathrm{~cm}$ in diameter.
Although LWD is generally small in most forested northeastern U.S. streams, canopy branches deposited from the 1998 ice storm formed large and complex structures by accumulating against channel-spanning trees or large boulders (Kraft et al. 2002; D.R. Warren, personal observation). In small Virginia streams, the amount of wood present in a pool has been associated with increased occupancy by trout (Flebbe 1999), and Hilderbrand et al. (1997) suggested that large volumes of wood added to a high-gradient stream could increase pool formation. In the Pacific Northwest and Alaska, the contribution of wood to pool formation varies in association with LWD loading (Montgomery et al. 1995; Martin 2001). Consequently, we expected that large-scale wood addition and debris-dam formation would increase trout habitat within a wood-deprived system. The sizes of the debris dams and boulders were not evaluated in the experimental manipulation because we were asking broad questions about the influence of debris dams on brook trout abundance in these systems. In light of our results, we acknowledge that evaluating debris-dam sizes could have helped to tease apart the relationship between debris dams and boulders and their relative contribution to pool formation, and we consider this a logical follow-up subject for investigation.

Overall, a positive response to wood removal, contradicting our expectations, was observed in five pairs of reaches 1 month after removal and in six pairs 1 year after removal. This may be attributed in some degree to substrate changes. The complex habitat formed by boulders and cobble is widely utilized by trout and salmon in many stream systems (Moore and Gregory 1988; Van Zyll De Jong et al. 1997; Berg et al. 1998), and wood removal has been found to increase substrate coarseness and the number of pools per reach in other studies conducted in high-gradient streams (Beschta 1979; Diez et al. 2000). We observed that substrate coarseness increased in the third-order removal reaches relative to the reference reaches from June 2000 to June 2001; during this period small boulders and cobble that had been previously 
buried in sediment were exposed (D.R. Warren and C.E. Kraft, unpublished data). Similar changes were not observed in the second-order study reaches.

Our hypotheses of decreased habitat and decreased trout abundance following wood removal were consistently supported in second-order streams 1 year after wood removal; overall trout abundance decreased significantly in the second-order removal reaches relative to the reference reaches. Although boulders and boulder pools were common in the second-order sites, the main dam in three of the four removal reaches formed against wood rather than boulders.

We attribute the variability and the lack of support for our hypotheses 1 month after wood removal to two major factors: preexisting complexity and low-flow conditions from August to September. In some cases, wood and dam removal did not entirely eliminate a pool. Instead, the primary poolforming elements consisted of boulders against which wood had accumulated, rather than the debris dams themselves. Study reaches were initially selected in May 2000, when stream flow was relatively high and all debris dams restricted stream flow. By August, large portions of many dams were above the stream surface and their removal did not influence flow. Surveys conducted under low-flow conditions may fail to fully evaluate the value of woody debris in creating refuge for fish during seasonal high flows (Solazzi et al. 2000; Roni and Quinn 2001).

The 1-year response to wood removal in both first- and third-order streams remained inconsistent. In first-order streams one pair indicated that wood removal decreased trout abundance, two pairs indicated that wood removal increased trout abundance, and one pair showed almost no response. Underlying geology and variable boulder-wood interactions, as in the 1-month response, likely contributed to this complex result. Some of the inconsistency between the first-order pairs may also be attributed to study design. By randomly pairing reaches instead of establishing specific paired comparisons based on debris-dam function (as in second- and third-order streams), we probably increased within- and between-pair variability.

In the third-order stream, we observed a large increase in trout abundance (although great variability was present in the estimates) in one removal reach but no major response in the other. The removal reach in the upstream pair was solely responsible for the statistically significant increase in trout abundance, and this reach contained the largest amount of unmoved debris (three pieces $>30 \mathrm{~cm}$ in diameter). Although the dams themselves were removed, wood remaining out of the water in late August probably functioned as a flow refuge during spring. Both third-order reaches also contained numerous boulders greater than $1 \mathrm{~m}$ in diameter, with several exceeding $2 \mathrm{~m}$ in diameter, that likely provided a flow refuge in the absence of wood.

By investigating the response of YOY trout to wood removal, we hoped to determine the influence of woody debris on YOY recruitment and the relative influence of wood removal on YOY and adult trout size classes. YOY responses were comparable to those of the larger fish, but we could not evaluate if differences in the number of YOY fish per reach were attributable to immigration, emigration, or recruitment.

We believe that the majority of observed changes in trout abundance were attributable to fish movement because reaches were relatively short, field collections occurred over only a 2-year period, and YOY recruitment was not clearly different between treatments. Brook trout are highly mobile and previous wood-addition studies have shown that increases in trout abundance can be linked to both decreased emigration and increased immigration (Burgess and Bider 1980; Riley and Fausch 1995; Gowan and Fausch 1996). Burgess and Bider (1980) found that increased trout abundance in woodaddition reaches was attributable to lower emigration rates, while both Riley and Fausch (1995) and Gowan and Fausch (1996) attributed increases in brook trout populations following wood addition to increased immigration.

The presence of "new" (untagged) 1+ fish in both the reference and the removal sites in our study reaches indicates that brook trout in our study system were also highly mobile. Two fish were observed to have moved between tributary systems, a distance greater than $1 \mathrm{~km}$. The lack of a significant difference in the number of "new" $1+$ fish between reference and removal sites in second-order streams in June or July 2001 suggests that, for the seasons during which we conducted our study, immigration rates remained similar between the two treatments. We conclude that in secondorder streams 1 year after removal - where a significant negative response to wood removal was observed - the emigration of trout from the two treatments differed, with a greater proportion of fish leaving wood-removal reaches.

The mobility of trout from season to season may account to some degree for the lack of a significant short-term response in all reaches and the lack of a 1-year response in first-order streams. In a study of woody-debris additions to 30 streams in Washington and Oregon, Roni and Quinn (2001) noted that seasonal reductions in the degree of competitive exclusion from refuge sites might account for different seasonal responses to wood addition by three salmonine species. Another study in Pacific coastal streams demonstrated that summer surveys may miss the habitat value of stream woody debris when fish aggregate at refuge areas during seasonal high flows - areas from which they disperse later in the spring (Solazzi et al. 2000). Late-spring dispersal from study reaches with woody debris and debris dams to reaches without wood could account for the lack of a significant response to wood removal in our first-order streams 1 year later. If woody debris is only fully utilized in these systems during high flows, then the lack of wood from July to September would have little influence on trout abundance.

Owing to the possible movement of trout between reaches during seasons when sampling was not conducted, we must confine our specific conclusions to trout use of woody debris in summer and early fall. The lack of a response during this time period suggests that habitat created by boulders is adequate in late summer for all of the streams that we studied, as well as during early summer to midsummer in the firstorder streams and the third-order stream.

The lack of a significant difference in trout abundance between second-order reaches with debris dams and reaches naturally devoid of wood confirms the response to wood removal seen in second-order streams over the same time period. This suggests that debris dams in this system created no additional low-flow habitat for trout where boulders had already created abundant pools and complex habitats. Since the no-wood reaches contained at least two full pool-riffle 
sequences, this evaluation selected reaches that already contained deep-water refuge habitat in summer. We did not survey trout abundance in the no-wood reaches 1 year following wood removal, therefore this longer term response was not evaluated in a similar manner.

The BACI study design facilitated analysis by removing potential variability due to environmental and biological interactions. By pairing reaches and conducting analyses on differences between pairs, we avoided potential confounding issues, such as the influence of other fishes (e.g., sculpins were consistently present or absent in both reaches within a pair) and differences in water temperature (e.g., one firstorder stream system was consistently cooler than the other). Other potentially confounding factors, such as probability of capture and handling mortality, appeared to be equal within paired reaches. The removal of this variability allowed us to attribute changes more directly to the experimental manipulation. Consistent seasonal trends in trout abundance in the reference and removal reaches and in the no-wood reaches before dam removal support the validity of using upstream reference reaches to account for seasonal and interannual changes.

The two primary criticisms of the simple BACI design were both addressed in this study (Schwarz 2002). The first criticism concerns the lack of temporal replication before and after the impact: we estimated fish abundance twice before and three times after wood removal. The second criticism, pseudoreplication with an inability to extrapolate results beyond a single location, was addressed by making the replicated unit the BACI pair. Such concerns regarding the simple BACI design appear justified because our results indicated that the response to wood removal varied over time between pairs and between streams.

Boulders are the dominant structural elements in our study area, where many of the rocks were larger in diameter than in-stream LWD or even streamside trees. The lack of an overall negative response to wood removal in many study reaches suggests that boulders can provide sufficient habitat complexity during low flow for brook trout populations in sections of high-gradient eastern Adirondack streams. The negative response to wood removal that was observed in second-order streams 1 year after removal does suggest, however, that wood addition may increase habitat in some areas. Streams with similar postglacial geological conditions within young forests will likely exhibit similar characteristics for both LWD and boulder function. Our manipulation in streams in the eastern Adirondack Mountains corroborates observational studies by Flebbe (1999), Inoue and Nakano (1998), and Berg et al. (1998) in which LWD created some habitat for trout in headwater streams, yet boulders provided the dominant structural habitat, supporting high densities of trout.

Based on trout responses to the removal of wood deposited by an ice storm, we expected to be able to make a broad and general inference regarding the indirect impacts of an ice storm on the local fish community through the deposition of woody debris. Overall, the observed variable response to wood removal does not allow for broad extrapolation. However, based on responses in second-order streams, where we evaluated four replicates and centered reaches on debris dams, we suggest that wood deposition in small streams as a result of ice storms will benefit brook trout, especially in areas with few boulders and (or) inadequate pool habitat.

\section{Acknowledgements}

Joshua Gorham and Jennifer DeMichele provided indispensible field assistance throughout two field seasons. Darby Kiley, Scott Krueger, Stephen Sebestyen, and Gina Zimmerman also provided helpful field assistance. We thank Alex Flecker, Darby Kiley, Andrew Milward, Barbara Peckarsky, George Pess, Tamara Smith, Brian Weidel, and an anonymous reviewer for helpful comments on the manuscript. Dan Josephson, Tim Patronski, and Rebecca Schneider provided useful assistance throughout the study. We thank Russell Lloyd and Evan Cooch for statistical assistance. We thank Kendal Southard and the Ward Lumber Company for access to study sites. This work was funded in part by the U.S. Forest Service Cooperative Lands Forest Health Monitoring Program and the Kieckhefer Adirondack Fellowship Program. The New York State Department of Environmental Conservation Division of Lands and Forests also provided logistical support.

\section{References}

Anderson, D.R., Link, W.A., Johnson, D.H., and Burnham, K.P. 2001. Suggestions for presenting the results of data analyses. J. Wildl. Manag. 65: 373-378.

Berg, N., Carlson, A., and Azuma, D. 1998. Function and dynamics of woody debris in stream reaches in the central Sierra Nevada, California. Can. J. Fish. Aquat. Sci. 55: 1807-1820.

Beschta, R.L. 1979. Debris removal and its effects on sedimentation in an Oregon coastal range stream. Northwest Sci. 53: 71-77.

Bilby, R.E. 1981. Role of organic debris dams in regulating the export of dissolved and particulate matter from a forested watershed. Ecology, 62: 1234-1243.

Bilby, R.E., and Likens, G.E. 1980. Importance of organic debris dams in the structure and function of stream ecosystems. Ecology, 61: 1107-1113.

Bisson, P.A., Bilby, R.E., Bryant, M.D., Dolloff, C.A., Grette, G.B., House, R.A., Murphy, M.L., Koski, K.V., and Sedell, J.R. 1987. Large woody debris in forested streams in the Pacific Northwest: past, present, and future. In Streamside management: forestry and fishery interactions. Edited by E.O. Salo and T.W. Cundy. University of Washington, Seattle. pp. 143-190.

Burgess, S.A., and Bider, J.R. 1980. Effects of stream habitat improvements on invertebrates, trout populations, and mink activity. J. Wildl. Manag. 44: 871-880.

Carle, F.L., and Strub, M.R. 1978. A new method for estimating population size from removal data. Biometrics, 34: 621-630.

Diez, J.R., Larranaga, S., Elosegi, A., and Pozo, J. 2000. Effect of removal of wood on streambed stability and retention of organic matter. J. North Am. Benthol. Soc. 19: 621-632.

Dolloff, C.A. 1986. Effects of stream cleaning on juvenile coho salmon and Dolly Varden in southeastern Alaska. Trans. Am. Fish. Soc. 115: 743-755.

Elliot, S.T. 1986. Reduction of a Dolly Varden population and macrobenthos after removal of logging debris. Trans. Am. Fish. Soc. 115: 392-400.

Flebbe, P.A. 1999. Trout use of woody debris and habitat in Wine Spring Creek, North Carolina. For. Ecol. Manag. 114: 367-376. 
Flebbe, P.A., and Dolloff, C.A. 1995. Trout use of woody debris and habitat in Appalachian wilderness streams of North Carolina. N. Am. J. Fish. Manag. 15: 579-590.

Gerard, P.D., Smith, D.R., and Weerakkody, G. 1998. Limits of retrospective power analysis. J. Wildl. Manag. 62: 801-807.

Gowan, C., and Fausch, K.D. 1996. Long-term demographic responses of trout populations to habitat manipulation in six Colorado streams. Ecol. Appl. 6: 931-946.

Grant, G.E., Swanson, F.J., and Wolman, M.G. 1990. Pattern and origin of stepped-bed morphology in high-gradient streams, Western Cascades, Oregon. Geol. Soc. Am. Bull. 102: 340-352.

Harmon, M.E., Franklin, J.F., Swanson, F.J., Sollins, P., Gregory, S.V., Lattin, J.D., Anderson, N.H., Cline, S.P., Aumen, N.G., Sedell, J.R., Lienkaemper, G.W., Cromack, K., Jr., and Cummins, K.W. 1986. Ecology of coarse woody debris in temperate ecosystems. Adv. Ecol. Res. 15: 133-302.

Hilderbrand, R.H., Lemly, D.A., Dolloff, C.A., and Harpster, K.L. 1997. Effects of large woody debris placement on stream channels and benthic macroinvertebrates. Can. J. Fish. Aquat. Sci. 54: 931-939.

Hunt, R.L. 1976. A long-term evaluation of trout habitat development and its relation to improving management-related research. Trans. Am. Fish. Soc. 105: 361-364.

Inoue, M., and Nakano, S. 1998. Effects of woody debris on the habitat of juvenile masu salmon (Oncorhynchus masou) in northern Japanese streams. Freshw. Biol. 40: 1-16.

Keller, E.A., and Swanson, F.J. 1979. Effects of large organic material on channel form and fluvial processes. Earth-Surf. Processes, 4: 361-380.

Kraft, C.E., Schneider, R.L., and Warren, D.R. 2002. Ice storm impacts on woody debris and debris dam formation in northeastern U.S. streams. Can. J. Fish. Aquat. Sci. 59: 1677-1684.

Manly, B.F.J. 1997. Randomization, bootstrap and Monte Carlo methods in biology. 2nd ed. Chapman and Hall, London.

Martin, D.J. 2001. The influence of geomorphic factors and geographic region on large woody debris loading and fish habitat in Alaska coastal streams. N. Am. J. Fish. Manag. 21: 429-440.

Maser, C., and Sedell, J.R. 1994. From the forest to the sea: the ecology of wood in streams, rivers estuaries, and oceans. St. Lucie Press, Delray Beach, Fla.

Montgomery, D.R., Buffington, J.M., Smith, R.D., Schmidt, K.M., and Pess, G. 1995. Pool spacing in forest channels. Water Resour. Res. 31: 1097-1105.
Moore, K.M.S., and Gregory, S.V. 1988. Response of young-ofthe-year cutthroat trout to manipulation of habitat structure in a small stream. Trans. Am. Fish. Soc. 117: 162-170.

Nislow, K.H., Folt, C.L., and Parrish, D.L. 1999. Favorable foraging locations for young Atlantic salmon: application to habitat and population restoration. Ecol. Appl. 9: 1085-1099.

Ralph, S.C., Poole, G.C., Conquest, L.L., and Naiman, R.J. 1994. Stream channel morphology and woody debris in logged and unlogged basins of western Washington. Can. J. Fish. Aquat. Sci. 51: 37-51.

Richmond, A.D., and Fausch, K.D. 1995. Characteristics and function of large woody debris in subalpine Rocky Mountain streams in northern Colorado. Can. J. Fish. Aquat. Sci. 52: 1789-1802.

Riley, S.C., and Fausch, K.D. 1995. Trout population response to habitat enhancement in six northern Colorado streams. Can. J. Fish. Aquat. Sci. 52: 34-53.

Roni, P., and Quinn, T.P. 2001. Density and size of juvenile salmonids in response to placement of large woody debris in western Oregon and Washington streams. Can. J. Fish. Aquat. Sci. 58: 282-292.

SAS institute Inc. 1999-2001. SAS System for Windows. Version 8.2. SAS institute Inc., Cary, N.C.

Schwarz, C.J. 2002. Real and quasi-experiments in capture-recapture studies. J. Appl. Stat. 29: 459-473.

Solazzi, M.F., Nickelson, T.E., Johnson, S.L., and Rodgers, J.D. 2000. Effects of increasing winter rearing habitat on abundance of salmonids in two coastal Oregon streams. Can. J. Fish. Aquat. Sci. 57: 906-914.

Sundbaum, K., and Naslund, I. 1998. Effects of woody debris on the growth and behavior of brown trout in experimental stream channels. Can. J. Zool. 76: 56-61.

Underwood, A.J. 1994. On beyond BACI: sampling designs that might reliably detect environmental disturbances. Ecol. Appl. 4: $3-15$.

Van Zyll De Jong, M.C., Cowx, I.B., and Scruton, D.A. 1997. An evaluation of instream habitat restoration techniques on salmonid populations in a Newfoundland stream. Regul. Rivers Res. Manag. 13: 603-614.

Wallace, J.B., Webster, J.R., and Meyer, J.L. 1995. Influence of log additions on physical and biotic characteristics of a mountain stream. Can. J. Fish. Aquat. Sci. 52: 2120-2137. 